\title{
Tumour stage and resection margin status are independent survival factors following partial pancreatoduodenectomy for duodenal adenocarcinoma
}

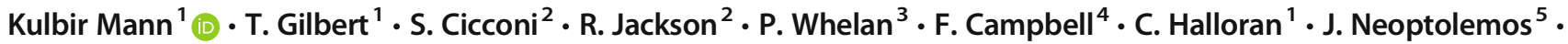 \\ P. Ghaneh ${ }^{1}$
}

Received: 26 October 2018 / Accepted: 20 March 2019 / Published online: 10 April 2019

(C) The Author(s) 2019

\begin{abstract}
Introduction There is limited published evidence on duodenal carcinoma due to its rarity. This study aimed to evaluate gastric outlet obstruction and obstructive jaundice along with pathological variables as survival factors in patients with duodenal adenocarcinoma following resection.

Methods Survival factor analysis was undertaken in patients undergoing duodenal cancer surgery from 1997 to 2015 in a single centre.

Results There were 57 patients of whom 18 had gastric outlet obstruction and 14 had obstructive jaundice. Fifty-three had a partial pancreatoduodenectomy and four had palliative bypass. Perioperative mortality and morbidity were $4 \%$ $(2 / 53)$ and $47 \%(25 / 53)$ respectively in resected patients. With a median (95\% confidence interval, CI) follow-up of 72 (57-86) months, median overall and recurrence-free survival was 38 months (95\% CI 28-113) and 27 months (95\% CI 18-83) respectively. The 1 and 3-year overall survival rates were $84 \%$ (95\% CI 74-95) and 52\% (95\% CI 39-69) respectively. Median overall survival was 19 months in patients with gastric outlet obstruction vs 53 months in those without $(p=0.026)$ and 28 months in patients with obstructive jaundice vs 38 months in those without $(p=0.611)$. Univariate analysis revealed that tumour stage, resection margin status, pre-operative albumin status, gastric outlet obstruction and age were associated with poorer overall and recurrence-free survival but multivariate analysis confirmed only tumour stage and resection margin status to be significant.

Conclusion Whereas gastric outlet obstruction in duodenal cancer appeared to be an important survival factor following partial pancreatoduodenectomy, multivariate analysis showed that only tumour stage and resection margin status were the key independent survival factors. Further multicentre studies are required to elucidate further characteristics of duodenal carcinoma and develop neoadjuvant/adjuvant management strategies.
\end{abstract}

Keywords Duodenal cancer · Obstructive jaundice · Gastric outlet obstruction

Work previously presented at the 48th Annual Meeting of the European Pancreatic Club, July 7, 2016

Kulbir Mann

Kulbir.Mann@liverpool.ac.uk

1 Department of Molecular and Clinical Cancer Medicine, Institution of Translational Medicine, University of Liverpool, 2nd Floor Sherrington Building, Ashton Street, Liverpool L69 3GE, UK

2 Statistics and Bioinformatics Unit, Cancer Research UK Liverpool Cancer Trials Unit, University of Liverpool, Block C, Waterhouse Building, 1-3 Brownlow Street, Liverpool L69 3GL, UK
3 Department of Surgery, Royal Liverpool University Hospital, Prescot Street, Liverpool L7 8XP, UK

4 Department of Pathology, Royal Liverpool University Hospital, Prescot Street, Liverpool L7 8XP, UK

5 Department of Surgery, University of Heidelberg, Im Neuenheimer Feld 110, 69120 Heidelberg, Germany 


\section{Introduction}

Duodenal adenocarcinoma is a rare malignancy; between 1998 and 2007, there were 2684 patients diagnosed in the UK and between 1997 and 2013, there were 2436 cases diagnoses in Germany [1]. The incidence is $0.4-0.6 / 10^{5}$ in men and marginally lower in women at $0.3-0.5 / 10^{5}$ with a 1 -year survival of $35.9 \%$ and $16.1 \%$ at 5 years [2]. These survival figures differ markedly from those in Germany and the USA. The 1-year age-adjusted relative survival rates in Germany and the USA were reported as $67.2 \%$ and $68.8 \%$ respectively and the 5 -year age-adjusted relative survival rates as $44.4 \%$ and $50.1 \%$ respectively [1]. Due to its low incidence, it is often grouped together with small bowel malignancy which accounts for $2 \%$ of all gastrointestinal tumours in the USA. Of all small bowel adenocarcinomas, $55.7 \%$ are located within the duodenum and $7 \%$ of periampullary tumours are duodenal in differentiation [3-5]. This infrequency in incidence has prevented the establishment of a thorough evidence base on which to derive uniform management and determine clinical and histopathological prognostic factors.

Initial clinical features are often insidious and more prominent when the lesion has grown to a size that can cause complications. There are vague symptoms of abdominal pain, nausea, vomiting, weight loss, fatigue and anorexia with some patients experiencing jaundice, gastrointestinal bleeding or gastric outlet obstruction $[4,5]$. Investigations commonly involve direct visualisation and biopsy in the form of endoscopy or cross-sectional computed tomography imaging. Patients may have to undergo stenting via endoscopic retrograde cholangiopancreatography to provide relief of jaundice or require enteral or parenteral nutritional support. Surgical resection remains the mainstay of curative treatment, in the form of pancreatoduodenectomy or in rarer cases segmental duodenal resection [3]. Patients who have dysplastic duodenal polyps, either single or part of a hereditary condition such as familial adenomatous polyposis, may have undergone submucosal resection or a pancreas-preserving duodenectomy $[6,7]$. There is very little published evidence regarding the use of neoadjuvant/adjuvant chemotherapy or radiotherapy. Some centres have treated duodenal adenocarcinoma similarly to periampullary tumours and use fluorouracil-based therapy and others as a colorectal malignancy and use oxaliplatinbased treatments $[4,5,8,9]$.

Due to the small number of cases, it has proved difficult to confidently identify survival factors although tumour size, lymph node status and resection margin status have often mentioned [5, 10-13]. In a single-centre study from Korea, the prognostic factors of 36 patients with duodenal cancer were analysed to find clear resection margin (R0), symptoms at initial admission, presence of lymph node metastasis, and perineural invasion significant only on univariate analysis [10]. The aim of this study was to include the specific presenting clinical features of obstructive jaundice and gastric outlet obstruction as part of the univariate and multivariate analysis of predictive survival factors.

\section{Material and methods}

All patients undergoing surgical exploration with a view to partial pancreatoduodenectomy for presumed duodenal carcinoma from 1 January 1997 to 31 December 2015 at the Royal Liverpool University Hospital were reviewed from a prospectively maintained pancreatobiliary database. Hereditary dysplastic duodenal polyps, ampullary tumours of duodenal origin and neuroendocrine lesions were excluded from the study. Data were obtained retrospectively from patient case notes and electronic records.

Data retrieved included patient demographics, timing of management, peri/post-operative details, tumour histology and stage, length of stay, adjuvant treatment, re-interventions/ readmissions and survival data. The TNM staging was standardised to the latest UICC version 8 [14]. Time to operation parameters are from initial diagnostic investigation to date of procedure and includes the time to multidisciplinary meeting. Length of stay results are overall time in the hospital inclusive of early pre-operative admissions. Post-operative complications were reported according to the Clavien-Dindo classification [15]. Patients who had a raised bilirubin of greater than $40 \mu \mathrm{mol} / \mathrm{L}$ were considered to have obstructive jaundice, and a record was made of pre-operative endoscopic retrograde cholangiopancreatography (ERCP) and percutaneous transhepatic cholangiography (PTC). Those patients admitted or transferred to this institution with symptoms of persistent vomiting and being unable to tolerate diet, correlating with an obstructive diagnosis on gastroscopy or oral contrast computer tomography $(\mathrm{CT})$ were recorded as gastric outlet obstruction.

Continuous variables are presented with their median and interquartile range (IQR), while categorical variables are described as frequency counts and proportion percentages. The Fisher exact test or Wilcoxon-Mann-Whitney test were performed as appropriate in order to compare proportions and distributions. Survival analysis was carried out for time to death and time to recurrence. Time to death was defined as the difference between date of death (or latest follow-up visit for living patients) and date of diagnosis. Time to recurrence was defined as the difference between the date of imaging demonstrating recurrence or date of death (or latest followup visit for living patients free from recurrence) and date of operation. For both these responses, median survival estimates from Kaplan-Meier method and their $95 \%$ confidence intervals (CIs) are reported. Cox proportional hazard models were initially fitted for each covariate independently and are presented as hazard ratios (HR) with 95\% CI [16]. Prognostic factors with a $p$ value less than 0.05 were further explored in 
Table 1 Patient cohort characteristics

\begin{tabular}{|c|c|c|c|c|c|c|c|}
\hline & \multirow{3}{*}{$\begin{array}{l}\text { Total } \\
N=57\end{array}$} & \multicolumn{3}{|c|}{ Gastric outlet obstruction } & \multicolumn{3}{|c|}{ Obstructive jaundice } \\
\hline & & \multicolumn{3}{|l|}{$N=51$} & \multicolumn{3}{|l|}{$N=52$} \\
\hline & & $\begin{array}{l}\text { No } \\
n=33\end{array}$ & $\begin{array}{l}\text { Yes } \\
n=18\end{array}$ & $p$ value & $\begin{array}{l}\text { No } \\
n=38\end{array}$ & $\begin{array}{l}\text { Yes } \\
n=14\end{array}$ & $p$ value \\
\hline \multicolumn{8}{|l|}{ Gender } \\
\hline $\begin{array}{l}\text { Female } \\
\text { Male }\end{array}$ & $\begin{array}{l}32(56 \%) \\
25(44 \%)\end{array}$ & $\begin{array}{l}13(39 \%) \\
20(61 \%)\end{array}$ & $\begin{array}{l}10(56 \%) \\
8(44 \%)\end{array}$ & 0.378 & $\begin{array}{l}16(42 \%) \\
22(58 \%)\end{array}$ & $\begin{array}{l}7(50 \%) \\
7(50 \%)\end{array}$ & 0.755 \\
\hline \multicolumn{8}{|l|}{ Age (years) } \\
\hline $\begin{array}{l}\text { Median } \\
\text { IQR }\end{array}$ & $\begin{array}{l}71 \\
(63.0-74.0)\end{array}$ & $\begin{array}{l}71 \\
(66.0-74.0)\end{array}$ & $\begin{array}{l}69 \\
(60.0-72.8)\end{array}$ & 0.252 & $\begin{array}{l}710 \\
(63.2-73.0)\end{array}$ & $\begin{array}{l}74 \\
(68.2-75.5)\end{array}$ & 0.129 \\
\hline \multicolumn{8}{|l|}{ Time to operation (days) } \\
\hline $\begin{array}{l}\text { Median } \\
\text { IQR }\end{array}$ & $\begin{array}{l}41 \\
(32.0-54.5)\end{array}$ & $\begin{array}{l}47 \\
(36.0-58.0)\end{array}$ & $\begin{array}{l}32 \\
(25.0-41.0)\end{array}$ & \multirow[t]{2}{*}{0.001} & $\begin{array}{l}40 \\
(30.5-48.8)\end{array}$ & $\begin{array}{l}48 \\
(35.0-57.0)\end{array}$ & \multirow[t]{2}{*}{0.323} \\
\hline No. of observations available & 47 & 29 & 17 & & 34 & 13 & \\
\hline \multicolumn{8}{|l|}{ Length of stay (days) } \\
\hline $\begin{array}{l}\text { Median } \\
\text { IQR }\end{array}$ & $\begin{array}{l}26 \\
(15.5-40.5)\end{array}$ & $\begin{array}{l}18 \\
(13.5-31.0)\end{array}$ & $\begin{array}{l}40 \\
(31.2-47.5)\end{array}$ & \multirow[t]{2}{*}{0.001} & $\begin{array}{l}23 \\
(14.0-39.0)\end{array}$ & $\begin{array}{l}32 \\
(21.2-49.0)\end{array}$ & \multirow[t]{2}{*}{0.146} \\
\hline No. of observations available & 47 & 31 & 16 & & 33 & 14 & \\
\hline
\end{tabular}

multivariable settings using backward selection technique based on Akaike Information Criterion for selecting the best model [17]. Proportional hazard assumption for Cox models was assessed with Schoenfeld residuals [18]. Kaplan-Meier curves and log-rank test were applied to investigate the difference in survival distribution between the clinical subgroup of interest. Median follow-up time was estimated with the reverse Kaplan-Meier method [19]. A $p$ value less than 0.05 was considered to be significant. All statistical analyses were performed with $\mathrm{R}$ version 3.3.0.

\section{Results}

There were 57 patients who had an attempted partial pancreatoduodenectomy for duodenal adenocarcinoma during the 18-year study period. The median age was of 71 (IQR 63.0-74.0) years and the female to male ratio of 1:0.78. Median time from the diagnosis to date of operation was 41 (IQR 32.0-54.5) days. Eighteen (32\%) patients presented with gastric outlet obstruction, and 12 of them were admitted prior to operation for enteral or parenteral nutritional support. There
Table 2 TNM staging for patients undergone successful resection

\begin{tabular}{|c|c|c|c|c|c|c|c|}
\hline & \multirow{3}{*}{$\begin{array}{l}\text { Total } \\
N=53\end{array}$} & \multicolumn{3}{|c|}{ Gastric outlet obstruction } & \multicolumn{3}{|c|}{ Obstructive jaundice } \\
\hline & & \multicolumn{3}{|l|}{$N=47$} & \multicolumn{3}{|l|}{$N=48$} \\
\hline & & $\begin{array}{l}\text { No } \\
n=31\end{array}$ & $\begin{array}{l}\text { Yes } \\
n=16\end{array}$ & $p$ value & $\begin{array}{l}\text { No } \\
n=37\end{array}$ & $\begin{array}{l}\text { Yes } \\
n=11\end{array}$ & $p$ value \\
\hline \multicolumn{8}{|c|}{ T stage } \\
\hline 1 & $2(4 \%)$ & $2(6 \%)$ & $0(0 \%)$ & \multirow[t]{4}{*}{0.068} & $1(3 \%)$ & $1(9 \%)$ & \multirow[t]{4}{*}{0.569} \\
\hline 2 & $7(13 \%)$ & $7(23 \%)$ & $0(0 \%)$ & & $5(14 \%)$ & $2(18 \%)$ & \\
\hline 3 & $15(28 \%)$ & $6(19 \%)$ & $7(44 \%)$ & & $12(32 \%)$ & $2(18 \%)$ & \\
\hline 4 & $29(55 \%)$ & $16(52 \%)$ & $9(56 \%)$ & & $19(51 \%)$ & $6(55 \%)$ & \\
\hline \multicolumn{8}{|c|}{$\mathrm{N}$ stage } \\
\hline 0 & $17(32 \%)$ & $10(32 \%)$ & $6(38 \%)$ & \multirow[t]{3}{*}{0.794} & $12(32 \%)$ & $4(36 \%)$ & \multirow[t]{3}{*}{0.217} \\
\hline 1 & $21(40 \%)$ & $13(42 \%)$ & $5(31 \%)$ & & $12(32 \%)$ & $6(55 \%)$ & \\
\hline 2 & $15(28 \%)$ & $8(26 \%)$ & $5(31 \%)$ & & $13(35 \%)$ & $1(9 \%)$ & \\
\hline \multicolumn{8}{|c|}{ R status } \\
\hline 0 & $43(81 \%)$ & $28(90 \%)$ & $9(56 \%)$ & \multirow[t]{2}{*}{0.020} & $28(76 \%)$ & $10(91 \%)$ & \multirow[t]{2}{*}{0.416} \\
\hline 1 & $10(19 \%)$ & $3(10 \%)$ & $7(44 \%)$ & & $9(24 \%)$ & $1(9 \%)$ & \\
\hline
\end{tabular}


were significantly lower levels of pre-operative serum albumin in patients presenting with gastric outlet obstruction compared to those without 34.0 (IQR 34.0-42.0) vs 38.0 (IGR $27.5-37.8) \mathrm{g} / \mathrm{L}$, respectively, $p=0.014$. Fourteen patients (25\%) presented at this or local institutions with obstructive jaundice and eight of them had successful pre-operative ERCP and stenting. Five patients had successful PTC and stenting, with a single failure. Despite these interventional procedures, there were still six patients who had bilirubin levels $>$ $100 \mu \mathrm{M} / \mathrm{L}$ on the day of operation. Information was not recorded in six patients with gastric outlet obstruction and five with obstructive jaundice respectively (Fig. 1). There were four patients who had both gastric outlet obstruction and obstructive jaundice but, for the purpose of this analysis, these were treated separately. Median time to operation was significantly shorter in patients with gastric outlet obstruction than without, 32 (IQR 25.0-41.0) days vs 47 (IQR 36.0-58.0) days respectively $[U=390, p$ value $=0.001]($ Table 1$)$.

Fifty-three (93\%) patients underwent a curative resection, and four (7\%) had a palliative gastric/biliary bypass procedure for local invasion or metastatic spread. Fifteen (28\%) patients undergoing resection had a classic Kausch Whipple procedure, and $38(72 \%)$ had a pylorus preserving pancreatoduodenectomy with three patients requiring a right hemicolectomy to complete tumour resection. A single patient had a splenectomy because of a suspicious lesion on preoperative staging, which was actually a lymphangioma. All histopathology results were collated including confirmation biopsies for patients in the bypass group. Fifty resected specimens were intestinal type duodenal carcinoma; two were mucinous type cancer and one with signet cell carcinoma. Nine patients (17\%) had tumour (T) staging of 1 or 2, 36 patients (68\%) had lymph node (LN) involvement and 43 patients $(81 \%)$ had tumour free resection margins (R0). It is worth noting that patients who had a right hemicolectomy were not more prevalent within a gastric outlet obstruction or obstructive jaundice group (Table 2).

There were two (4\%) post-operative deaths following resection both due to myocardial infarction. There were 30 postoperative complications in $24(47 \%)$ patients: 21 ClavienDindo grade II, six with grade III and three with grade IV. Fourteen $(26 \%)$ patients had intra-abdominal collections, of which six $(11 \%)$ were associated with pancreatic leaks and they were managed conservatively with antibiotics in eight cases and interventional drainage in six cases. There were three incidences of delayed gastric emptying $(6 \%)$ that required total parenteral nutrition. The remaining postoperative morbidities consisted of six (11\%) patients with surgical site infections, five (9\%) patients with respiratory complications, one (2\%) patient with an acute kidney injury and one $(2 \%)$ patient with an upper arm deep vein thrombosis. No significant differences in post-operative course or complications rates were found in patients presenting with gastric outlet obstruction or obstructive jaundice compared to those without either. The median length of total hospital stay (which included pre-operative admission for nutritional supplementation) in
Fig. 1 A CONSORT flow diagram demonstrating the cohorts of patients with obstructive jaundice and gastric outlet obstruction

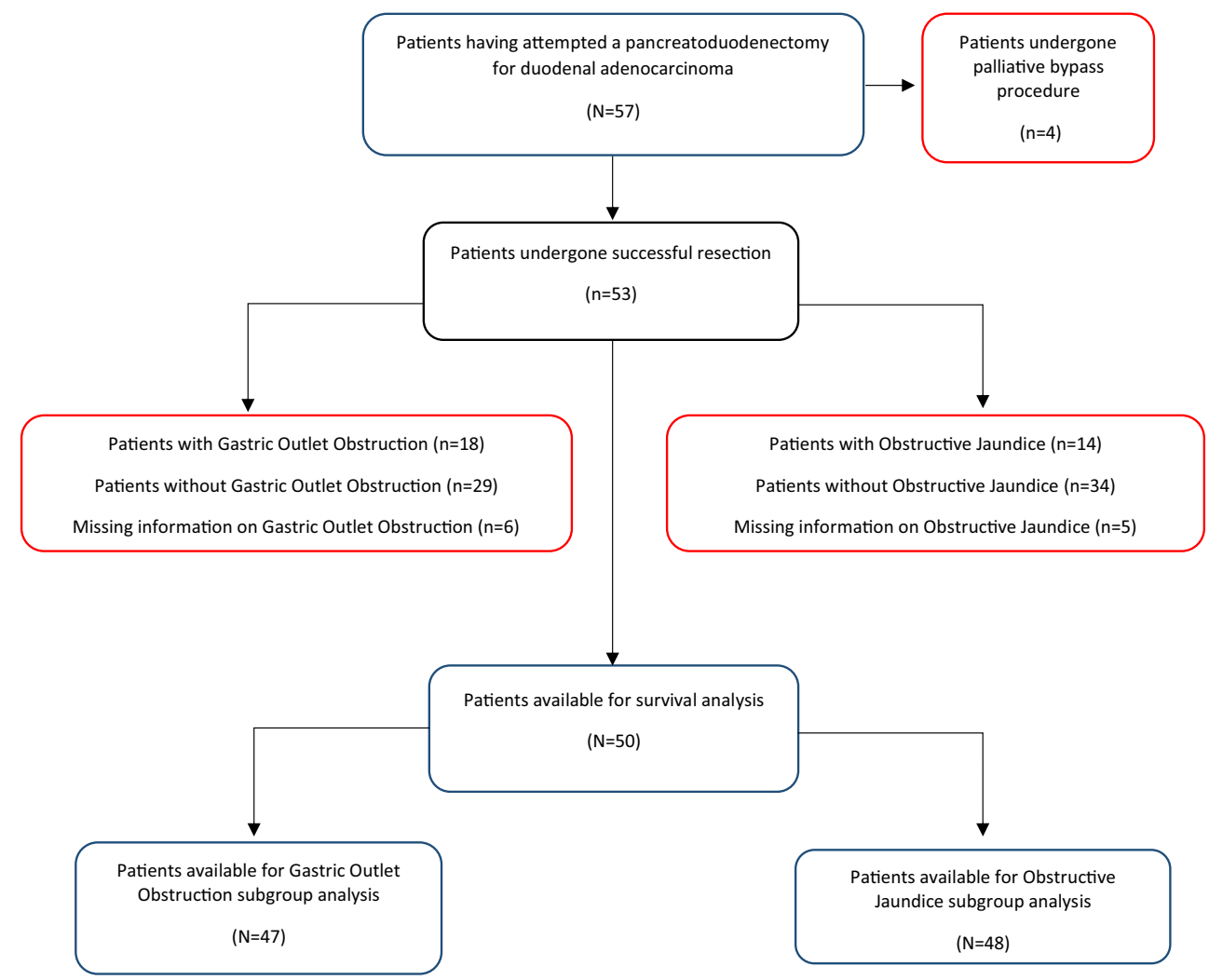


patients with gastric outlet obstruction was 40 (IQR 31.247.5) days compared to 18 (IQR 13.5-31.0) days for patients without gastric outlet obstruction $[U=102, p$ value $=0.001]$ (Fig. 2). The median pre-surgery length of hospital stay in patients with gastric outlet obstruction was 13 (IQR 10.126.0) days compared to 0 (IQR 0.4-5.9) days in those without gastric outlet obstruction.

Eighteen (32\%) patients underwent adjuvant chemotherapy, and two (4\%) patients had adjuvant chemoradiotherapy. Ten were treated with capecitabine as a single therapy regimen, whereas three patients had gemcitabine monotherapy and three patients had 5-fluorouracil monotherapy. A further four patients had dual drug regimens involving folinic acid, 5fluorouracil, capecitabine and oxaliplatin. Thirty (53\%) patients that did not receive any adjuvant chemotherapy because

a)

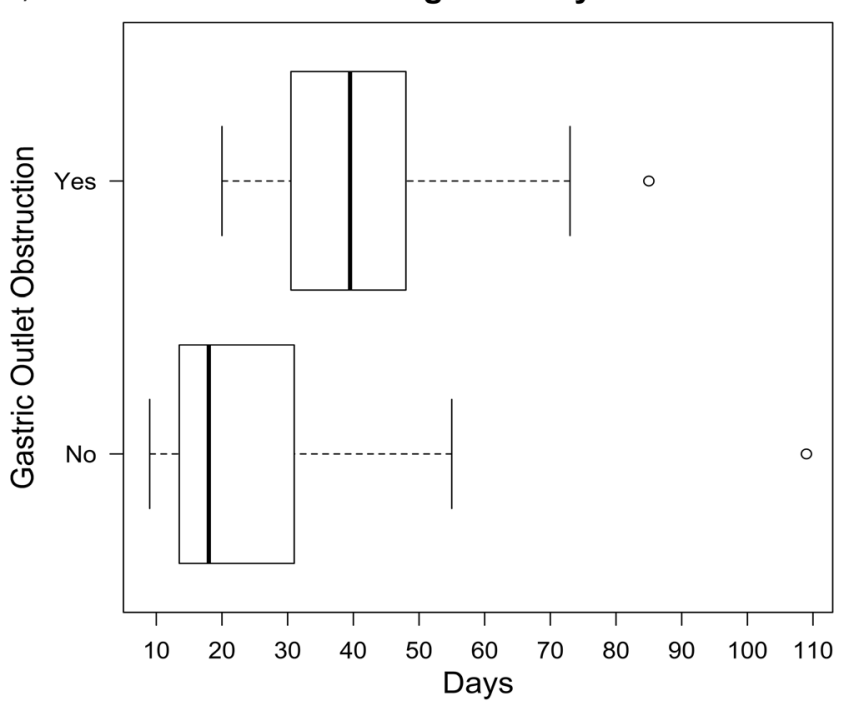

b)

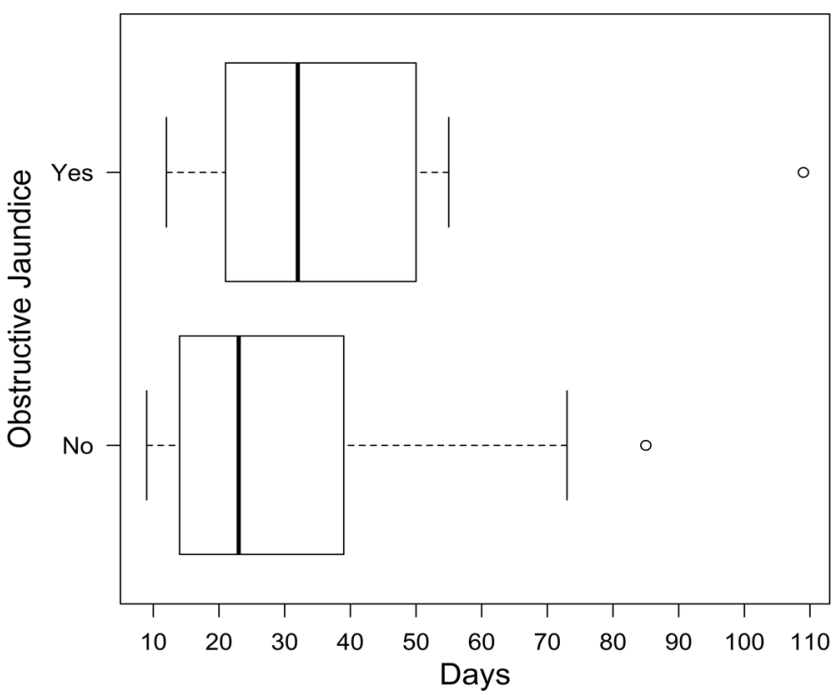

Fig. 2 Box plot distributions of length of stay in patients with a gastric outlet obstruction and $\mathbf{b}$ obstructive jaundice preoperatively of poor performance status in 16 patients, oncology advice in nine patients, personal choice with two patients and death in three patients. Records were not available in seven cases. Though a lack of consistent therapies, the use of any adjuvant therapy did not have a significant effect on patient survival, $[\mathrm{HR}=0.88(95 \% \mathrm{CI} 0.40-1.92), p$ value $=0.742]$.

The median follow-up time was 72 (95\% CI 57-86) months. The median overall survival (OS) time was 38 (95\% CI 28 113 ) months, with 1- and 3-year survival rates of $84 \%(95 \% \mathrm{CI}$ 74-95) and 53\% (95\% CI 39-69) respectively. The median recurrence-free survival (RFS) was 27 (95\% CI 18-83) months, with 1- and 3-year recurrence-free survival rates of $72 \%(95 \%$ CI: 61-86) and 45\% (95\% CI: 33-61) respectively (Fig. 3). The median OS time was 19 months (95\% CI 11-unobtainable) in the group of patients presenting with gastric outlet obstruction and 53 (95\% CI 31-unobtainable) months in patients presenting without [log-rank $\chi_{\mathrm{df}=1}^{2}=4.96, p$ value $\left.=0.026\right]$ (Fig. 4a). Although without reaching statistical significance, similar trends were reported with respect to time to recurrence, 16 (95\% CI 7-unobtainable) months vs 47 (95\% CI 21-unobtainable) months for patients with and without gastric outlet obstruction respectively [log-rank $\chi_{\mathrm{df}=1}^{2}=3.13, p$ value $=$ 0.077] (Fig. 4b). No differences in overall survival or recurrence-free survival were detected between patients having obstructive jaundice or not (Fig. 5).

Univariate Cox models showed that resection margin status, tumour stage and pre-operative albumin levels were related to both time to death and time to recurrence (Tables 3 and 4). Gastric outlet obstruction was also associated with overall survival, and age was associated with recurrence-free survival. Multivariable Cox regression identified resection margin status $[\mathrm{HR}=5.83$ (95\% CI 2.25-15.07), $p$ value $<0.001]$ and tumour stage $[\mathrm{HR}=2.27$ (95\% CI 1.02-5.04), $p$ value $=$ $0.040]$ as predictive factors for overall survival (Table 5). The best model for recurrence-free survival included resection margin status $[\mathrm{HR}=4.48$ (95\% CI 1.95-10.28), $p$ value $<$ $0.001]$, age $[\mathrm{HR}=1.06(95 \%$ CI $1.01-1.11), p$ value $=$ 0.012 ] and tumour stage $[\mathrm{HR}=2.28(95 \% \mathrm{CI} 1.07-4.86), p$ value $=0.070$ ], although the latter did not reach the significance level in the multivariable setting (Tables 5 and 6).

\section{Discussion}

This study has shown that advanced tumour stage, positive resection margins, low pre-operative albumin levels, the presence of gastric outlet obstruction and advanced age were each associated with shorter overall and recurrencefree survival following partial pancreatoduodenectomy for duodenal cancer. On multivariate analysis however, only tumour stage and resection margin status were of independent significance. This indicates that whereas gastric outlet obstruction in duodenal cancer appeared to be an important 
Fig. 3 Kaplan-Meier estimates of median survival and recurrencefree survival with $95 \%$ confidence intervals of duodenal adenocarcinoma patients with a gastric outlet obstruction and $\mathbf{b}$ obstructive jaundice preoperatively a)

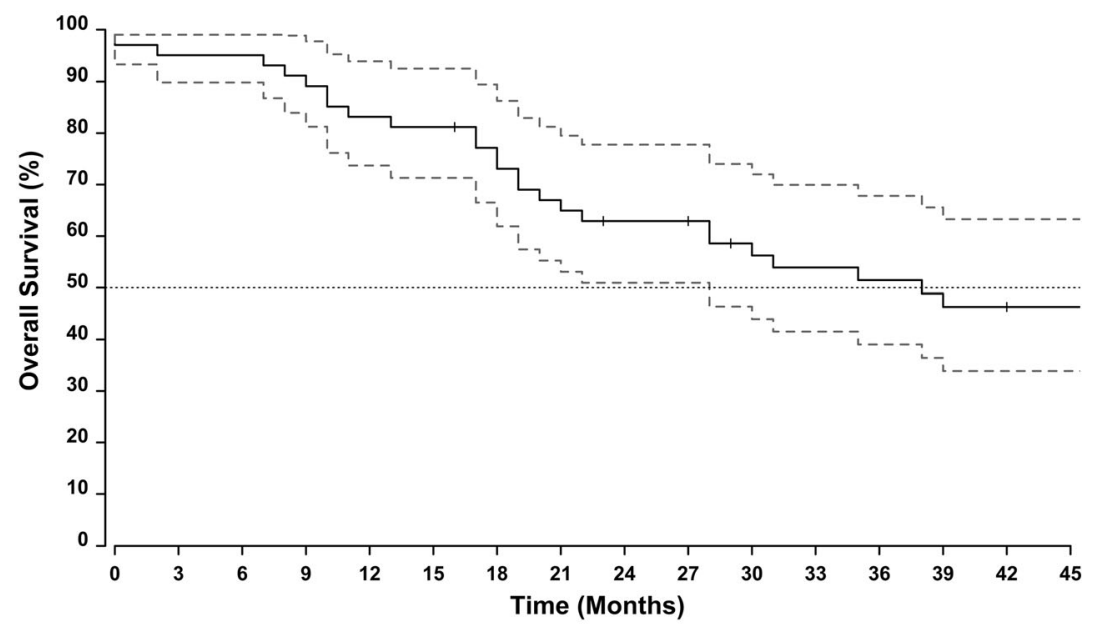

Numbers at risk

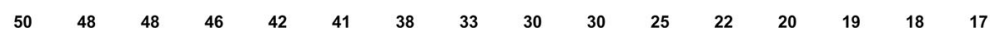

b)

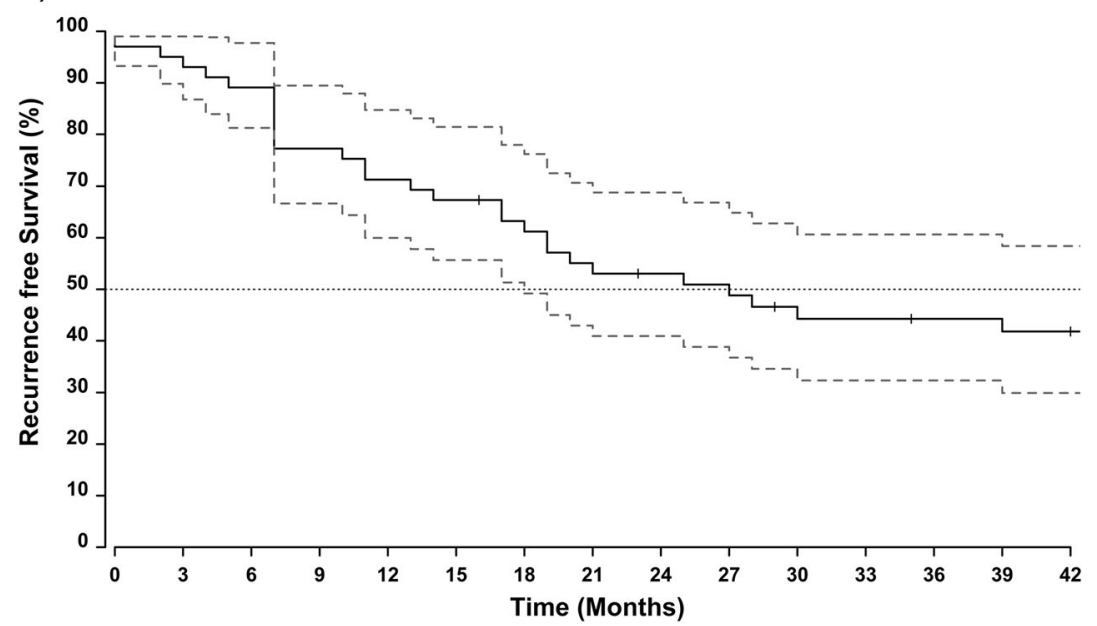

Numbers at risk

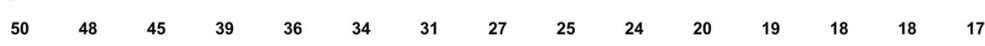

survival factor per se, the symptom of obstruction signified a larger tumour diameter. The challenges in removing a larger tumour are reflected in the greater frequency of positive margins in this group and points to the need for an effective neoadjuvant and/or adjuvant strategy.

The Royal Liverpool University Hospital serves a catchment area of over 400,000 people and acts as a tertiary referral centre for hepatobiliary disease for a much larger populace of approximately 2.4 million and represents a relatively large single-centre experience. This compares to a series of 178 patients over 13 years from six other large centres in the UK [13], whilst other studies including those from the USA and Japan have reviewed from 21 to 122 patients [5, 10, 12, 20-24]. In the present study, only four $(7 \%)$ patients underwent a palliative procedure which is less than that observed in two larger cohort studies reflecting the quality of pre-operative workup and technical surgery $[12,13,25]$. There were only two (4\%) post-operative deaths both due to myocardial infarction. The morbidity rate of $47 \%$ is similar to those published in previous studies of approximately 40-46\% [5, $12,13,22,23]$. The majority $(70 \%)$ of complications were Clavien-Dindo grade II requiring only medical intervention. The proportion of patients with a pancreatic leak was $11 \%$, in keeping with a published range of 9.3-28.9\% $[5,12,13,21,22]$. The delayed gastric emptying rate of $6 \%$ is lower than the reported rates of $12.5-24 \%[5,12$, $13,22,23]$.

The median overall survival in duodenal adenocarcinoma is approximately $35.5-83$ months in published series [5, 12, $13,22,23]$. The median overall survival of 38 months in our study is at the lower end of this range but much improved from previous United Kingdom figures and recent German and US publications $[1,2]$. Negative resection margin status and 
Fig. 4 Kaplan-Meier estimates of median survival by clinical sub groups of a obstructive jaundice and $\mathbf{b}$ gastric outlet obstruction a)

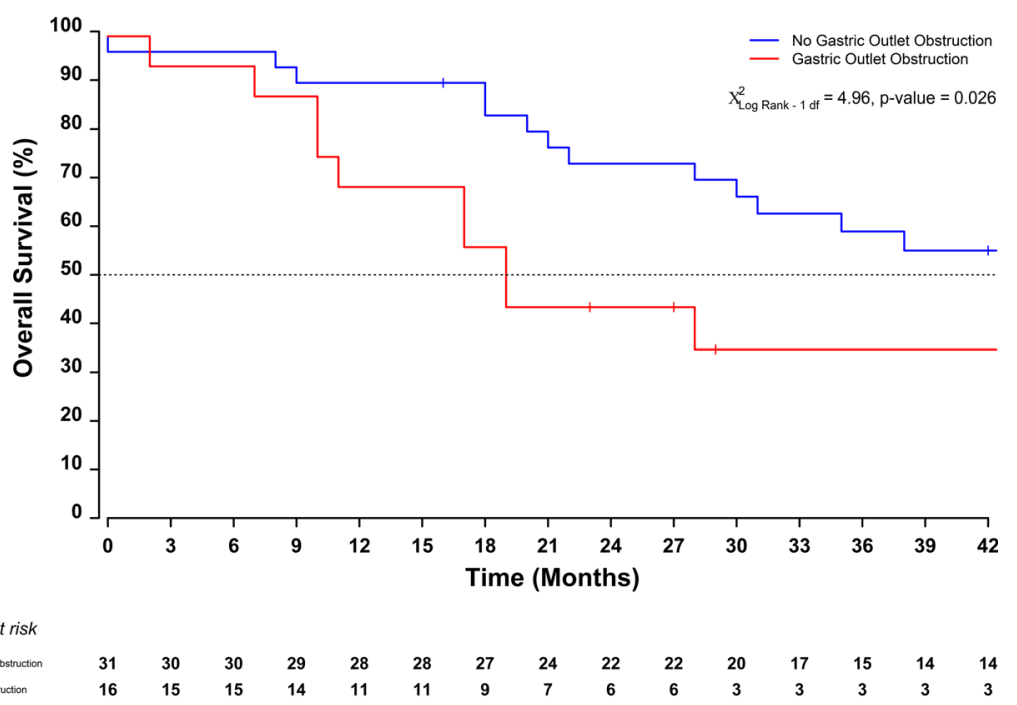

b)

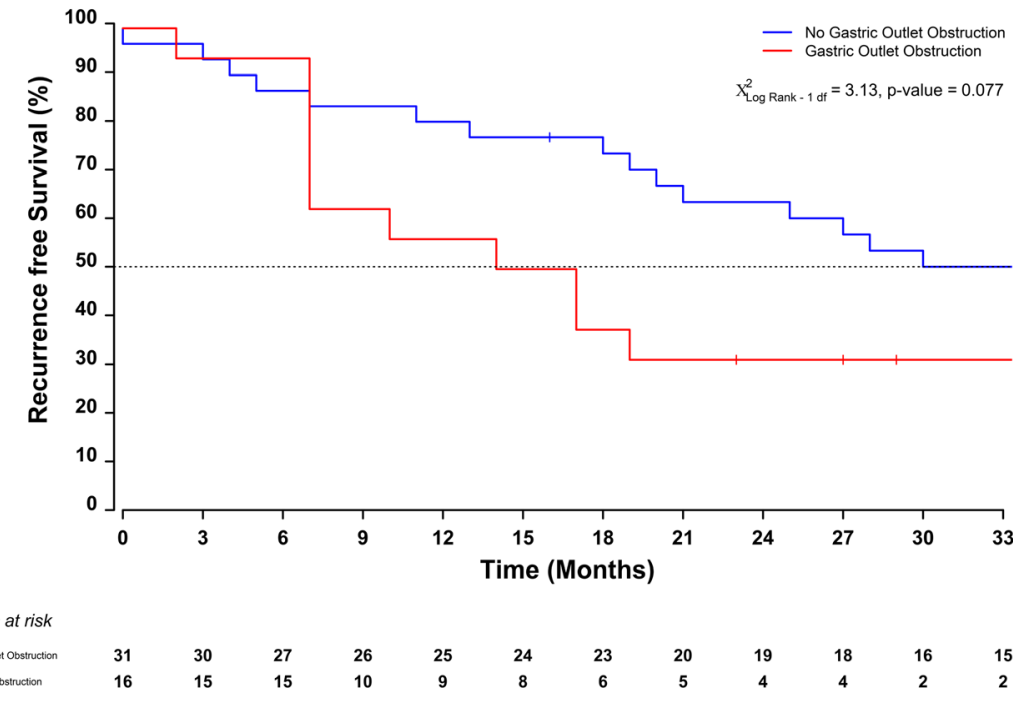

tumour stage III or lower were associated with longer survival. Published series have not consistently found lymph node status to be a significant prognostic factor $[4,5,12,13,25,26]$. Interestingly, age seemed to be a prognostic factor for recurrence-free survival which has been described recently in a German observational study [27]. A study of small bowel cancers based on the USA Surveillance, Epidemiology, and End Results (SEER) database from 2004 to 2013 found that duodenal localization was associated with worse overall survival and that young age, retrieval of more than 12 regional lymph nodes, less advanced stage and married matrimonial status were positive, independent prognostic factors [1].

There is no standard of adjuvant chemotherapy in patients with resected duodenal adenocarcinoma. In our study, 20 patients $(35 \%)$ underwent chemotherapy or chemoradiotherapy, and ten of these had the same drug regimen (capecitabine). The ESPAC-3 periampullary trial, which included 80 intestinal type tumours, found an increase in median survival of 7.9 months comparing a chemotherapy group (5fluorouracil plus folinic acid) to an observation group [28]. This is the only randomised phase three trial pertinent to duodenal carcinoma, but there have been three phase II studies that have observed the benefit of chemotherapy on advanced small bowel tumours. Response rates of $18.4 \%$ were reported using 5-fluorouracil, doxorubicin, and mitomycin $\mathrm{C}$ and a rate of $50 \%$ more recently utilising capecitabine and oxaliplatin [8, 9]. Adding irinotecan to capecitabine and oxaliplatin has given a response rate of $37 \%$ in the latest phase II trial of 33 patients [29]. Due to the lack of robust adjuvant chemotherapy trials the rate of adjuvant therapy is quite variable $[4,5,12$, 13]. The use of radiotherapy in duodenal cancer has been studied even less, and propensity score-matched analysis of national observational oncological data from the US and South Korea has been reported. They observed that radiation 
Fig. 5 Kaplan-Meier estimates of median time to recurrence by clinical sub groups of a obstructive jaundice and $\mathbf{b}$ gastric outlet obstruction

a)

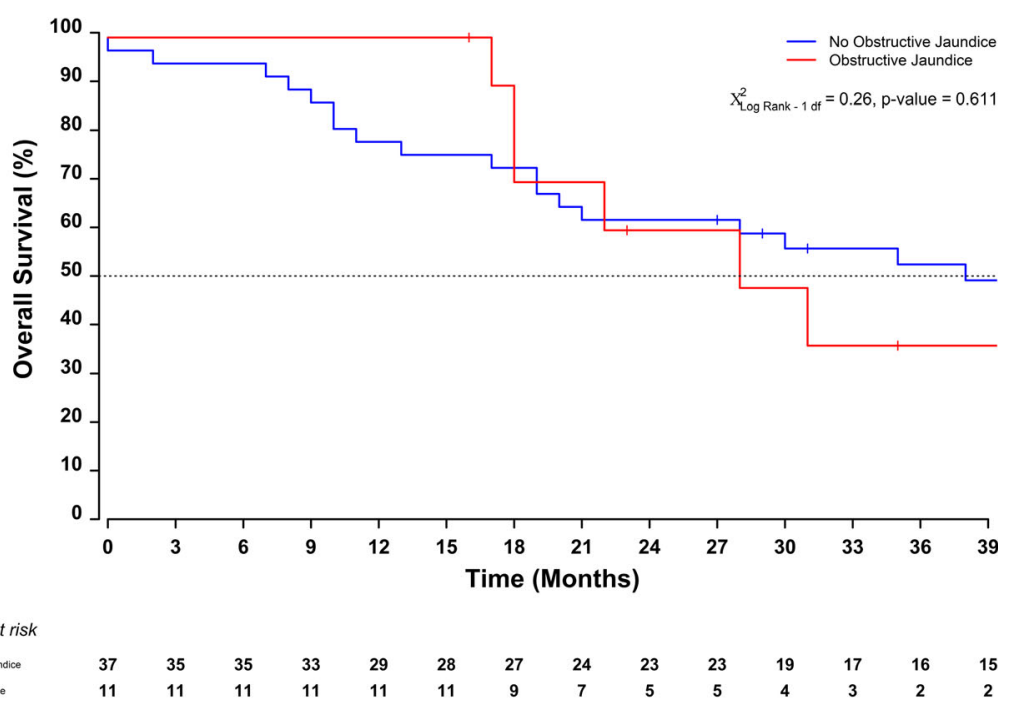

b)

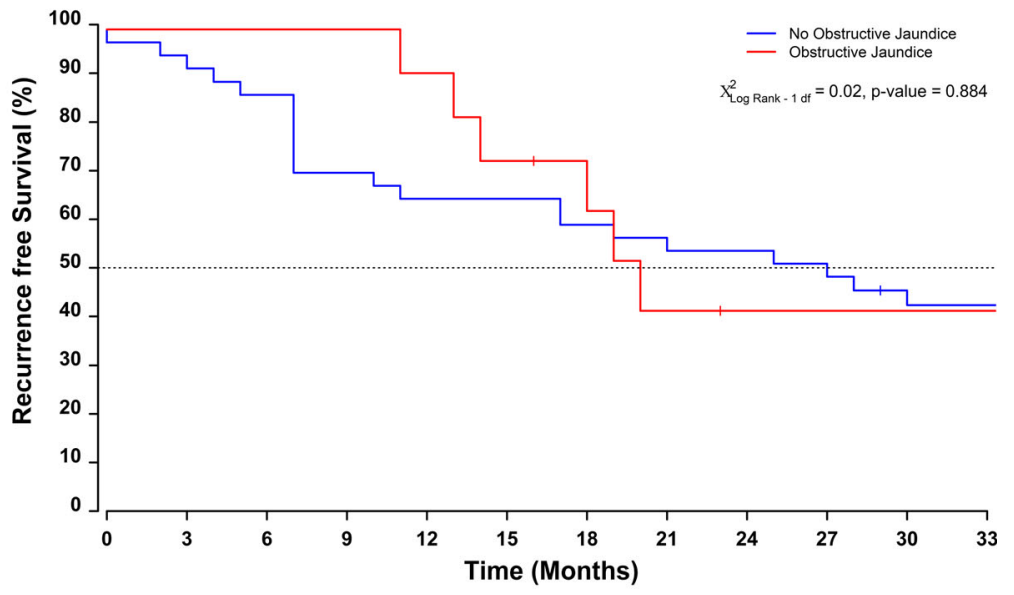

Numbers at risk

provides minimal survival benefit in addition to adjuvant chemotherapy but may have a role in locally advanced disease [30, 31].

There have been no published studies specifically reviewing the effects of obstructive jaundice and gastric outlet obstruction on the outcomes of duodenal adenocarcinoma. The Korean single-centre study grouped together presenting symptoms (abdominal pain, vomiting, gastrointestinal bleeding, dyspepsia, weight loss, jaundice, diarrhoea and oedema) as part of a multivariate analysis and found no significant prognostic factors [10]. In the present study, we included the specific presenting clinical features of obstructive jaundice and gastric outlet obstruction as part of the predictive modelling, given that one or other of these clinical features might influence clinical decision-making. The systemic effects of obstructive jaundice on patients with pancreatic ductal adenocarcinoma have been well established, and preoperative biliary drainage with metal stenting is routine in some centres. However, others undertake immediate resection without biliary stenting and some centres are employing a "fast track" pathway for pancreatoduodenectomy procedures [32-35]. In the present study, obstructive jaundice at presentation was not associated with pathological staging, resectability, postoperative complications and survival. Patients presenting with gastric outlet obstruction required a longer overall length of hospital stay to improve nutritional status. Pre-operative serum albumin levels were significantly lower in these patients with gastric outlet obstruction reflecting the nutritional deficit and the development of a cachexia associated with cancer [36]. Although gastric outlet obstruction was associated with reduced survival on univariate analysis, this was not supported once other prognostic factors were taken onto account. The impact of gastric outlet obstruction is complex because it incorporates greater proportions of high tumour staging and 
Table 3 Univariate Cox models for time to death

\begin{tabular}{|c|c|c|c|}
\hline Variable & Hazard ratio $(95 \% \mathrm{CI})$ & Log-rank $\chi^{2}$ & $p$ value \\
\hline \multicolumn{4}{|l|}{ Gender } \\
\hline Female & 1 & \multirow[t]{2}{*}{0.15} & \multirow[t]{2}{*}{0.697} \\
\hline Male & $1.15(0.56-2.36)$ & & \\
\hline Age (years) & $1.03(0.99-1.08)$ & 2.03 & 0.154 \\
\hline \multicolumn{4}{|l|}{ T stage } \\
\hline $3-$ & 1 & \multirow[t]{2}{*}{8.59} & \multirow[t]{2}{*}{0.003} \\
\hline 4 & $2.97(1.39-6.35)$ & & \\
\hline \multicolumn{4}{|l|}{$\mathrm{N}$ stage } \\
\hline 0 & 1 & \multirow[t]{2}{*}{1.92} & \multirow[t]{2}{*}{0.166} \\
\hline $1+$ & $1.76(0.78-3.95)$ & & \\
\hline \multicolumn{4}{|l|}{ R status } \\
\hline 0 & 1 & \multirow[t]{2}{*}{25.74} & \multirow[t]{2}{*}{$<0.001$} \\
\hline 1 & $7.88(3.11-19.96)$ & & \\
\hline Albumin $(\mathrm{g} / \mathrm{L})$ & $0.94(0.89,0.99)$ & 5.33 & 0.021 \\
\hline \multicolumn{4}{|c|}{ Gastric outlet obstruction } \\
\hline No & 1 & \multirow[t]{2}{*}{4.96} & \multirow[t]{2}{*}{0.026} \\
\hline Yes & $2.30(1.08-4.90)$ & & \\
\hline \multicolumn{4}{|c|}{ Obstructive jaundice } \\
\hline No & 1 & \multirow[t]{2}{*}{0.26} & \multirow[t]{2}{*}{0.611} \\
\hline Yes & $1.25(0.53-2.96)$ & & \\
\hline \multicolumn{4}{|c|}{ Adjuvant treatment } \\
\hline No & 1 & \multirow[t]{2}{*}{0.11} & \multirow[t]{2}{*}{0.742} \\
\hline Yes & $0.88(0.40-1.92)$ & & \\
\hline
\end{tabular}

Table 4 Univariate Cox models for time to recurrence

\begin{tabular}{|c|c|c|c|c|c|c|c|}
\hline Variable & Hazard ratio $(95 \% \mathrm{CI})$ & Log-rank $\chi^{2}$ & $p$ value & Conclu & & & \\
\hline Gender & & & & & & & \\
\hline Female & 1 & 0.10 & 0.758 & Partial pan & atoduodenectomy wi & sufficient ly & h node \\
\hline Male & $1.12(0.56-2.23)$ & & & clearance $\mathrm{i}$ & he only effective treat & nt for duode & cancer \\
\hline Age (years) & $1.05(1.00-1.09)$ & 3.59 & 0.058 & achieving & ger disease free and & erall surviva & From a \\
\hline T stage & & & & practice pe & ective, patients presen & g with obstru & ve jaun- \\
\hline $3-$ & 1 & 6.82 & 0.009 & dice and/or & stric outlet obstructior & ould not be a & imed to \\
\hline 4 & $2.56(1.23,5.31)$ & & & have a poo & rognosis but be consid & d for curativ & section \\
\hline N stage & & & & with an em & asis on nutrition and & eticulous op & tive ap- \\
\hline 0 & 1 & 2.34 & 0.126 & proach $\mathrm{Tl}_{1}$ & ar stage and resecti & maroin stat & are key \\
\hline $\begin{array}{c}1+ \\
\text { R status }\end{array}$ & $1.85(0.83,4.12)$ & & & $\begin{array}{l}\text { proach. It } \\
\text { independe }\end{array}$ & $\begin{array}{l}\text { our stage and resect1 } \\
\text { survival factors indic }\end{array}$ & $\begin{array}{l}\text { margin stat } \\
\text { ig a need fo }\end{array}$ & $\begin{array}{l}\text { are key } \\
\text { ffective }\end{array}$ \\
\hline 0 & 1 & 18.34 & $<0.001$ & neoadjuvar & ind/or adjuvant treatm & & \\
\hline 1 & $5.06(2.23,11.49)$ & & & & & & \\
\hline Albumin $(\mathrm{g} / \mathrm{L})$ & 0.95 & 4.57 & 0.032 & Table $6 \mathrm{M}$ & variate Cox model for tim & recurrence & \\
\hline Gastric outlet ol & $\begin{array}{l}(0.90,1.00) \\
\text { uction }\end{array}$ & & & Variable & Hazard ratio $(95 \%$ CI) & Log-rank $\chi^{2}$ & $p$ value \\
\hline No & 1 & 3.13 & 0.077 & & & & \\
\hline Yes & $1.93(0.92-4.03)$ & & & R status & & & \\
\hline Obstructive jaul & & & & 0 & 1 & 12.68 & $<0.001$ \\
\hline No & 1 & 0.02 & 0.884 & 1 & $4.48(1.95-10.28)$ & & \\
\hline Yes & $1.07(0.45,2.51)$ & & & T stage & & & \\
\hline Adjuvant treatn & & & & $3-$ & 1 & 3.29 & 0.070 \\
\hline No & 1 & 0.00 & 0.975 & 4 & $2.28(1.07-4.86)$ & & \\
\hline Yes & $0.99(0.47-2.082)$ & & & Age (years) & $1.06(1.01-1.11)$ & 6.29 & 0.012 \\
\hline
\end{tabular}

Table 5 Multivariate Cox model for time to death

\begin{tabular}{llll}
\hline Variable & Hazard ratio $(95 \% \mathrm{CI})$ & Log-rank $\chi^{2}$ & $p$ value \\
\hline R status & & & \\
0 & 1 & 16.20 & $<0.001$ \\
1 & $5.83(2.25-15.07)$ & & \\
T stage & & 4.22 & 0.040 \\
$3-$ & 1 & & \\
4 & $2.27(1.02-5.04)$ & & \\
\hline
\end{tabular}

positive resection margins which are independently significant factors. As a presenting symptom, it reflects multiple aspects of tumour staging and the study may be underpowered to demonstrate its significance. Its importance should not be overlooked and efficient pre-optimisation and meticulous operative preparations should be undertaken.

The limitations of this study are the relatively small number of patients and its retrospective nature. The study is strengthened however in being from a single centre and with sufficient number of events for each of the outcomes for statistical modelling. The duration of our study is over 18 years and there have been significant changes to the clinical practice and postoperative management of patients, especially with the implementation of Enhanced Recovery after Surgery (ERAS) protocols. This has had an impact on the post-operative outcomes and length of stay of patients $[4,5,12,13]$.

.


Authors' contributions $\mathrm{KM}$ and $\mathrm{PG}$ participated in study conception and design. KM, TG and PW participated in the acquisition of data. KM, FC, $\mathrm{SC}$ and RJ participated in the analysis and interpretation of data. $\mathrm{KM}, \mathrm{TG}$ and SC participated in the drafting of the manuscript. PG, FC, CH and JN participated in the critical revision of the manuscript.

\section{Compliance with ethical standards}

There were no funding contributions to this study. There are no conflicts of interest. There are separate conflicts of interest submissions for all authors. As a retrospective, this study does not contain any studies with animals or human participants.

Open Access This article is distributed under the terms of the Creative Commons Attribution 4.0 International License (http:// creativecommons.org/licenses/by/4.0/), which permits unrestricted use, distribution, and reproduction in any medium, provided you give appropriate credit to the original author(s) and the source, provide a link to the Creative Commons license, and indicate if changes were made.

\section{References}

1. Pulte D, Weberpals J, Schroder CC, Emrich K, Holleczek B, Katalinic A, Luttmann S, Sirri E, Jansen L, Brenner H, Group GCSW (2018) Survival of patients with hepatobiliary tract and duodenal cancer sites in Germany and the United States in the early 21st century. Int J Cancer J Int Cancer 143(2):324-332

2. Coupland VH, Kocher HM, Berry DP, Allum W, Linklater KM, Konfortion J, Moller H, Davies EA (2012) Incidence and survival for hepatic, pancreatic and biliary cancers in England between 1998 and 2007. Cancer Epidemiol 36(4):e207-e214

3. Bilimoria KY, Bentrem DJ, Wayne JD, Ko CY, Bennett CL, Talamonti MS (2009) Small bowel cancer in the United States: changes in epidemiology, treatment, and survival over the last 20 years. Ann Surg 249(1):63-71

4. Cloyd JM, George E, Visser BC (2016) Duodenal adenocarcinoma: advances in diagnosis and surgical management. World $\mathrm{J}$ Gastrointest Surg 8(3):212-221

5. Poultsides GA, Huang LC, Cameron JL, Tuli R, Lan L, Hruban RH, Pawlik TM, Herman JM, Edil BH, Ahuja N, Choti MA, Wolfgang CL, Schulick RD (2012) Duodenal adenocarcinoma: clinicopathologic analysis and implications for treatment. Ann Surg Oncol 19(6):1928-1935

6. Al-Sarireh B, Ghaneh P, Gardner-Thorpe J, Raraty M, Hartley M, Sutton R, Neoptolemos JP (2008) Complications and follow-up after pancreas-preserving total duodenectomy for duodenal polyps. Br J Surg 95(12):1506-1511

7. Hamada K, Takeuchi Y, Ishikawa H, Ezoe Y, Arao M, Suzuki S, Iwatsubo T, Kato M, Tonai Y, Shichijo S, Yamasaki Y, Matsuura N, Nakahira H, Kanesaka T, Yamamoto S, Akasaka T, Hanaoka N, Higashino K, Uedo N, Ishihara R, Okada H, Iishi H (2018) Safety of cold snare polypectomy for duodenal adenomas in familial adenomatous polyposis: a prospective exploratory study. Endoscopy 50(5):511-517

8. Gibson MK, Holcroft CA, Kvols LK, Haller D (2005) Phase II study of 5-fluorouracil, doxorubicin, and mitomycin C for metastatic small bowel adenocarcinoma. Oncologist 10(2):132-137

9. Overman MJ, Varadhachary GR, Kopetz S, Adinin R, Lin E, Morris JS, Eng C, Abbruzzese JL, Wolff RA (2009) Phase II study of capecitabine and oxaliplatin for advanced adenocarcinoma of the small bowel and ampulla of Vater. J Clin Oncol : Off J Am Soc Clin Oncol 27(16):2598-2603
10. Kim MJ, Choi SB, Han HJ, Park PJ, Kim WB, Song TJ, Suh SO, Choi SY (2014) Clinicopathological analysis and survival outcome of duodenal adenocarcinoma. Kaohsiung J Med Sci 30(5):254-259

11. Onkendi EO, Boostrom SY, Sarr MG, Farnell MB, Nagorney DM, Donohue JH, Kendrick ML, Lombardo KM, Haddock MG, Que FG (2012) Neoadjuvant treatment of duodenal adenocarcinoma: a rescue strategy. J Gastrointest Surg : Off J Soc Surg Alimentary Tract 16(2):320-324

12. Onkendi EO, Boostrom SY, Sarr MG, Farnell MB, Nagorney DM, Donohue JH, Kendrick ML, Reid-Lombardo KM, Harmsen WS, Que FG (2012) 15-year experience with surgical treatment of duodenal carcinoma: a comparison of periampullary and extraampullary duodenal carcinomas. J Gastrointest Surg : Off J Soc Surg Alimentary Tract 16(4):682-691

13. Solaini L, Jamieson NB, Metcalfe M, Abu Hilal M, Soonawalla Z, Davidson BR, McKay C, Kocher HM, Group UKDCS (2015) Outcome after surgical resection for duodenal adenocarcinoma in the UK. Br J Surg 102(6):676-681

14. Brierley JGWC, (2016) TNM Classification of Malignant Tumours, 8th Edition. Wiley-Blackwell,

15. Dindo D, Demartines N, Clavien PA (2004) Classification of surgical complications: a new proposal with evaluation in a cohort of 6336 patients and results of a survey. Ann Surg 240(2):205-213

16. Cox DR (1992) Regression models and life-tables. Springer Series in Statistics, Springer New York

17. Akaike H (1974) A new look at the statistical model identification. IEEE Trans Autom Control 19(6):716-723

18. D S (1982) Partial residuals for the proportional hazards regression model. Biometrika 69(1):239-241

19. Schemper M, Smith TL (1996) A note on quantifying follow-up in studies of failure time. Control Clin Trials 17(4):343-346

20. Kawahira H, Miura F, Saigo K, Matsunaga A, Natsume T, Akai T, Horibe D, Suzuki K, Nabeya Y, Hayashi H, Miyauchi H, Shuto K, Asano T, Matsubara H (2011) Survival predictors of patients with primary duodenal adenocarcinoma. Int Surg 96(2):111-116

21. Lee SY, Lee JH, Hwang DW, Kim SC, Park KM, Lee YJ (2014) Long-term outcomes in patients with duodenal adenocarcinoma. ANZ J Surg 84(12):970-975

22. Shamali A, McCrudden R, Bhandari P, Shek F, Barnett E, Bateman A, Abu Hilal M (2016) Pancreaticoduodenectomy for nonampullary duodenal lesions: indications and results. Eur $\mathrm{J}$ Gastroenterol Hepatol 28(12):1388-1393

23. Lee CH, Shingler G, Mowbray NG, Al-Sarireh B, Evans P, Smith M, Usatoff V, Pilgrim C (2017) Surgical outcomes for duodenal adenoma and adenocarcinoma: a multicentre study in Australia and the United Kingdom. ANZ J Surg 88(3):e157-e161

24. Cecchini S, Correa-Gallego C, Desphande V, Ligorio M, Dursun A, Wargo J, Fernandez-del Castillo C, Warshaw AL, Ferrone CR (2012) Superior prognostic importance of perineural invasion vs. lymph node involvement after curative resection of duodenal adenocarcinoma. J Gastrointest Surg : Off J Soc Surg Alimentary Tract 16(1):113-120

25. Jiang QL, Huang XH, Chen YT, Zhang JW, Wang CF (2016) Prognostic factors and clinical characteristics of patients with primary duodenal adenocarcinoma: a single-center experience from China. Biomed Res Int 2016:6491049

26. Ecker BL, McMillan MT, Datta J, Dempsey DT, Karakousis GC Fraker DL, Drebin JA, Mamtani R, Giantonio BJ, Roses RE (2016) Lymph node evaluation and survival after curative-intent resection of duodenal adenocarcinoma: a matched cohort study. Eur J Cancer 69:135-141

27. Wilhelm A, Galata C, Beutner U, Schmied BM, Warschkow R, Steffen T, Brunner W, Post S, Marti L (2018) Duodenal localization is a negative predictor of survival after small bowel adenocarcinoma resection: a population-based, propensity score-matched analysis. J Surg Oncol 117(3):397-408 
28. Neoptolemos JP, Moore MJ, Cox TF, Valle JW, Palmer DH, McDonald AC, Carter R, Tebbutt NC, Dervenis C, Smith D, Glimelius B, Charnley RM, Lacaine F, Scarfe AG, Middleton MR, Anthoney A, Ghaneh P, Halloran CM, Lerch MM, Olah A, Rawcliffe CL, Verbeke CS, Campbell F, Buchler MW, European Study Group for Pancreatic C (2012) Effect of adjuvant chemotherapy with fluorouracil plus folinic acid or gemcitabine vs observation on survival in patients with resected periampullary adenocarcinoma: the ESPAC-3 periampullary cancer randomized trial. Jama 308(2):147-156

29. McWilliams RR, Foster NR, Mahoney MR, Smyrk TC, Murray JA, Ames MM, Horvath LE, Schneider DJ, Hobday TJ, Jatoi A, Meyers JP, Goetz MP (2017) North Central Cancer Treatment Group N0543 (Alliance): a phase 2 trial of pharmacogeneticbased dosing of irinotecan, oxaliplatin, and capecitabine as firstline therapy for patients with advanced small bowel adenocarcinoma. Cancer 123(18):3494-3501

30. Ecker BL, McMillan MT, Datta J, Lee MK, Karakousis GC, Vollmer CM Jr, Drebin JA, Fraker DL, Roses RE (2017) Adjuvant chemotherapy versus chemoradiotherapy in the management of patients with surgically resected duodenal adenocarcinoma: a propensity score-matched analysis of a nationwide clinical oncology database. Cancer 123(6):967-976

31. Lim YJ, Kim K (2017) Effect of postoperative radiotherapy on survival in duodenal adenocarcinoma: a propensity score-adjusted analysis of Surveillance, Epidemiology, and End Results database. Int J Clin Oncol 23(3):473-481

32. Sauvanet A, Boher JM, Paye F, Bachellier P, Sa Cuhna A, Le Treut YP, Adham M, Mabrut JY, Chiche L, Delpero JR, French
Association of S (2015) Severe jaundice increases early severe morbidity and decreases long-term survival after pancreaticoduodenectomy for pancreatic adenocarcinoma. J Am Coll Surg 221(2):380-389

33. van der Gaag NA, Rauws EA, van Eijck CH, Bruno MJ, van der Harst E, Kubben FJ, Gerritsen JJ, Greve JW, Gerhards MF, de Hingh IH, Klinkenbijl JH, Nio CY, de Castro SM, Busch OR, van Gulik TM, Bossuyt PM, Gouma DJ (2010) Preoperative biliary drainage for cancer of the head of the pancreas. N Engl J Med 362(2):129-137

34. Smith RA, Dajani K, Dodd S, Whelan P, Raraty M, Sutton R, Campbell F, Neoptolemos JP, Ghaneh P (2008) Preoperative resolution of jaundice following biliary stenting predicts more favourable early survival in resected pancreatic ductal adenocarcinoma. Ann Surg Oncol 15(11):3138-3146

35. Roberts KJ, Prasad P, Steele Y, Marcon F, Faulkner T, Cilliers H, Dasari B, Abradelo M, Marudanayagam R, Sutcliffe P, Mirza DF, Isaac J (2017) A reduced time to surgery within a 'fast track' pathway for periampullary malignancy is associated with an increased rate of pancreatoduodenectomy. HPB (Oxford) 19(8):713-720

36. Esper DH, Harb WA (2005) The cancer cachexia syndrome: a review of metabolic and clinical manifestations. Nutr Clin Pract : Off Publ Am Soc Parenter Enter Nutr 20(4):369-376

Publisher's note Springer Nature remains neutral with regard to jurisdictional claims in published maps and institutional affiliations. 